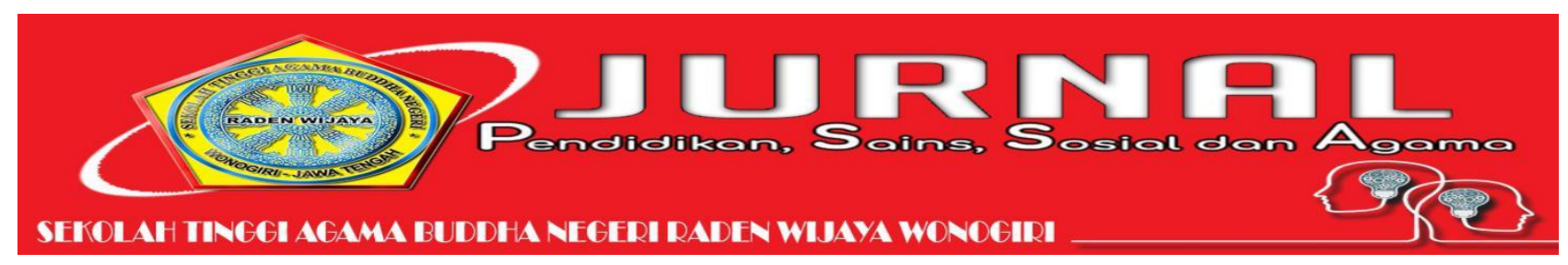

\title{
PENGARUH MODEL PEMBELAJARAN KOOPERATIF TIPE STAD TERHADAP PRESTASI BELAJAR MATEMATIKA SISWA SMA
}

\author{
Siska Endah Nurani, Afif Afghohani, Annisa Prima Exacta \\ Universitas Veteran Bangun Nusantara Sukoharjo \\ siskaendah24@gmail.com
}

\begin{abstract}
Abstrak
Penelitian ini bertujuan untuk mengetahui ada tidaknya pengaruh model pembelajaran kooperatif tipe Student Team Achievement Division (STAD) terhadap prestasi belajar matematika siswa kelas X MIPA 3 SMA Negeri 1 Weru tahun pelajaran 2019/ 2020. Populasi dari penelitian ini adalah seluruh siswa kelas X MIPA SMA Negeri 1 Weru dengan jumlah seluruh populasi adalah 144 siswa. Sampel pada penelitian ini adalah kelas X MIPA 3 sebagai kelas eksperimen yang menggunakan pembelajaran STAD dan kelas X MIPA 4 sebagai kelas kontrol yang menggunakan pembelajaran konvensional. Sampel diambil menggunakan teknik cluster random sampling. Berdasarkan hasil uji hipotesis dengan taraf segnifikan sebesar 5\%, diperoleh harga $t_{\text {hitung }}=2,0771$ lebih besar dari harga $t_{\text {tabel }}=t_{(0,025,70)}=1,994$ maka dapat disimpulkan bahwa ada pengaruh model pembelajaran kooperatif tipe Student Team Achievement Division (STAD) terhadap prestasi belajar matematika siswa kelas X MIPA 3 SMA Negeri 1 Weru.
\end{abstract}

Kata Kunci: Prestasi Belajar, Matematika; Student Team Achievement Division, Pembelajaran Kooperatif

\begin{abstract}
This study aims to determine whether there is an effect of the cooperative learning model type Student Team Achievement Division (STAD) on mathematics learning achievement in class X MIPA 3 SMA Negeri 1 Weru in the 2019/2020 academic year. The population of this study were all students of class $X$ MIPA SMA Negeri 1 Weru with a total population of 144 students. The sample in this study was class $X$ MIPA 3 as an experimental class using STAD learning and class X MIPA 4 as a control class using conventional learning. Samples were taken using cluster random sampling technique. Based on the results of hypothesis testing with a significant level of 5\%, the value of $t$ count $=2.0771$ is greater than the price of $t$ table $=t_{((0.025 .70))}=1.994$, it can be denied that there is an effect of the cooperative learning model type Student Team Achievement Division (STAD) on the achievement of learning mathematics class X MIPA 3 SMA Negeri 1 Weru.
\end{abstract}

Key: Learning Achievement, Mathematics,; Student Team Achievement Division, Cooperative Learning 


\section{PENDAHULUAN}

Pendidikan merupakan hal penting dalam kehidupan. Menurut UU No 20 Tahun 2003, Pendidikan adalah usaha sadar dan terencana untuk mewujudkan suasana belajar dan proses pembelajaran agar peserta didik secara aktif mengembangkan potensi dirinya untuk memiliki kekuatan spititual keagamaan, pengendalian diri, kepribadian, kecerdasan, akhlak mulia, serta keterampilan yang diperlukan dirinya, masyarakat, bangsa dan negara. Namun, dari hasil observasi ternyata masih banyak sekolah memiliki prestasi belajar yang rendah terutama pada mata pelajaran eksak. Usaha yang dapat dilakukan untuk membantu siswa dalam mengembangkan kecerdasannya salah satunya adalah dengan menerapkan model pembelajaran yang inovatif.

Salah satu mata pelajaran yang dipelajari di sekolah adalah matematika. Menurut Susanto (2012: 118) pengertian matematika adalah sebagai berikut:

a. Matematika adalah cabang ilmu pengetahuan eksak dan terorganisir secara sistematik.

b. Matematika adalah pengetahuan tentang bilangan dan kalkulasi.

c. Matematika adalah pengetahuan tentang penalaran logik dan berhubungan dengan bilangan.

d. Matematika adalah pengetahuan tentang fakta - fakta kuantitatif dan masalah tentang ruang dan bentuk.

e. Matematika adalah pengetahuan tentang struktur - struktur yang logik.

f. Matematika adalah pengetahuan tentang aturan aturan yang ketat.

Matematika merupakan salah satu mata pelajaran yang dianggap sulit. Banyak siswa yang tidak menyukainya dan membosankan sehingga diperlukan model pembelajaran yang dapat memberikan semangat siswa untuk belajar matematika dan mempermudah siswa dalam memahami materi.

Ada banyak model pembelajaran yang dapat digunakan. Yang paling sederhana yaitu pembelajaran Student Team Achievement Division (STAD).

Pembelajaran STAD merupakan pembelajaran yang lebih menekankan kepada sistem kerja/ belajar kelompok yang tersruktur dengan jumlah siswa yang dibatasi pada tiap kelompoknya dengan tujuan agar hasil belajar dapat tercapai secara maksimal (Giyanti, 2018: 43).

Isjoni (dalam Priansa, 2017: 320) menyatakan bahwa tujuan model pembelajaran STAD adalah mengubah perilaku belajar peserta didik dari individualistik menjadi kerja sama tim yang mendorong peserta didik untuk saling membantu satu dengan yang lainnya. Selain itu, tujuan model pembelajaran kooperatif tipe STAD adalah menumbuhkan rasa tanggung jawab, baik individu maupun kelompok sehingga memperoleh hasil yang memuaskan untuk mendapatkan penghargaan kelompok (Priansa, 2017:320).

Menurut Slavin (dalam Priansa, 2017: 327) pembelajaran STAD memiliki tahapan sebagai berikut:

a. Menyampaikan tujuan pembelajaran yang akan dicapai dan memotivasi siswa untuk giat belajar.

b. Pembagian kelompok, setiap kelompok terdiri atas empat atau lima siswa dengan kemampuan yang heterogen.

c. Presentasi kelas, guru menjelaskan garis besar materi yang akan dipelajari dan menjelaskan kemampuan yang diharapkan dapat dikuasai siswa.

d. Kegiatan belajar kelompok, siswa bekerja dalam kelompok. Dalam hal ini guru memberikan lembar kerja. Selama kegiatan kelompok guru bertindak sebagai fasilitator. Kegiatan ini merupakan ciri terpenting dalam STAD.

e. Kuis, dilakukan untuk mengevaluasi hasil belajar siswa mengenai materi yang dipelajari. Dalam mengerjakan kuis, siswa tidak boleh bekerja sama dengan kata lain kuis ini bersifat individu. Skor yang diperoleh pada kuis ini dapat menggambarkan sampai dimana pemahaman siswa.

f. Penghargaan Prestasi, guru memberikan penghargaan kepada siswa yang melampaui batas penguasaan. Skor kuis dapat 
digunakan sebagai acuan untuk pemberian hadiah.

Berdasarkan uraian di atas dapat disimpulkan bahwa pembelajaran STAD merupakan model pembelajaran yang menerapkan kegiatan belajar kelompok dengan jumlah anggota yang dibatasi dan memiliki kemampuan yang heterogen pada setiap kelompoknya agar timbul rasa saling membantu antar anggota guna memperoleh penghargaan kelompok.

Pada dasarnya penggunaan model pembelajaran diharapkan dapat memperbaiki atau meningkatkan prestasi belajar siswa. Hidajat (2018: 16) berpendapat bahwa belajar merupakan suatu aktivitas mental atau psikis yang berlangsung dalam interaksi aktif dengan lingkungan yang menghasilkan perubahan dalam pengetahuan pemahaman , keterampilan dan nilai sikap. Sedang prestasi belajar memiliki pengertian yaitu hasil usaha belajar yang dicapai seseorang siswa berupa suatu kecakapan dari kegiatan belajar bidang akademik disekolah pada jangka waktu tertentu yang dicatat pada setiap akhir semester di dalam buku laporan yang disebut rapor (Thaib, 2013: 387).

Baik tidaknya prestasi belajar dapat dipengaruhi oleh beberapa faktor. Hamdani (2011: 139) menggolongkannya menjadi dua bagian yaitu faktor internal dan faktor eksternal. Faktor internal meliputi kecerdasan (inteligensi), jasmani, sikap, minat, bakat, dan motivasi. Sedangkan faktor eksternal meliputi kadaan keluarga, keadaan sekolah, dan keadaan masyarakat.

\section{METODE}

Penelitian akan dilaksanakan di SMA Negeri 1 Weru, Sukoharjo Tahun Pelajaran 2019/ 2020 semester genap. Jenis penelitian ini adalah penelitian eksperimen semu, yaitu penelitian yang dilakukan untuk mencari hubungan sebab akibat antara dua faktor yang sengaja ditimbulkan oleh peneliti dengan mengeliminasi atau mengurangi atau menyisihkan faktor - faktor lain yang mengganggu dengan kata lain penelitian ini dimaksudkan untuk melihat akibat dari suatu perlakuan (Arikunto, 2013: 9). Populasi pada penelitian ini adalah seluruh siswa kelas $\mathrm{X}$ MIPA SMA Negeri 1 Weru. Dengan teknik cluster random sampling diperoleh sampel yaitu, kelas $\mathrm{X}$ MIPA 3 sebagai kelas eksperimen yang menggunakan pembelajaran STAD dan kelas X MIPA 4 sebagai kelas konrol yang menggunakan pembelajaran konvensional.

Pada penelitian ini membutuhkan dua data yaitu data nilai PAS gasal tahun pelajaran 2019/2020 dan nilai test prestasi belajar dari kelas sampel. Nilai PAS kelas sampel digunakan untuk mengetahui apakah kedua kelas memiliki kemampuan awal sama atau tidak. Nilai tes prestasi belajar diperoleh melalui tes tertulis setelah melakukan proses pembelajaran menggunakan model pembelajaran tersebut. Sebelum diujikan, instrumen tes prestasi belajar di uji coba guna mengetahui apakah instrumen sudah memenuhi syarat tes yang baik. Syarat yang dimaksud adalah uji reliabelitsas, uji validitas, uji tingkat kesukaran dan uji daya pembeda. Nilai tes prestasi belajar digunakan untuk membuktikan kebenaran hipotesis. Hipotesis pada penelitian ini adalah ada pengaruh model pembelajaran kooperatif tipe Student Team Achievement Division (STAD) terhadap prestasi belajar matematika siswa kelas $\mathrm{X}$ MIPA 3 SMA Negeri 1 Weru tahun pelajaran 2019/ 2020.

Teknik analisis data yang digunakan adalah uji normalitas dengan metode uji liliefors untuk mengetahui apakah data berasal dari populasi yang berdistribusi normal atau tidak, uji homogenitas dengan metode uji $\mathrm{f}$ (fisher) untuk mengetahui apakah kedua kelas memiliki variansi yang sama atau tidak (homogen) dan uji t. Taraf segnifikan yang digunakan sebesar $5 \%$. Untuk mengetahui apakah kedua kelas memiliki kemampuan awal yang sama atau tidak digunakan metode uji t, tetapi sebelumnya dari data nilai PAS harus melalui uji prasyarat yaitu uji normalitas dan uji homogenitas. Hal ini juga berlaku untuk mengetahui kebenaran hipotesis, nilai tes prestasi belajar harus diuji prasyarat setelah itu dilakukan uji hipotesis menggunakan metode uji t. Hipotesis pada penelitian ini adalah ada pengaruh model pembelajaran kooperatif tipe Student Team Achievement 
Division (STAD) terhadap prestasi belajar matematika siswa kelas X MIPA 3 SMA Negeri 1 Weru, Sukoharjo tahun pelajaran 2019/ 2020.

\section{HASIL}

Dari nilai PAS gasal tahun pelajaran 2019/2020 kelas X MIPA 3 diperoleh banyak sampel $(\mathrm{n})=36$, nilai terendah $=38$, nilai tertinggi $=94$, mean $(\overline{\mathrm{x}})=55$, modus $=46$ dan 54 , median $=54$, simpangan baku $(\mathrm{S})=$ 11,1149 , dan variansi $\left(\mathrm{S}^{2}\right)=123,5428$. Sedangkan untuk kelas X MIPA 4 diperoleh banyak sampel $(\mathrm{n})=36$, nilai terendah $=40$, nilai tertinggi $=74$, mean $(\overline{\mathrm{x}})=53,444$, modus $=54$, median $=54$, simpangan baku $(\mathrm{S})=$ 8,5069 , dan variansi $\left(S^{2}\right)=72,3682$.

Berdasarkan uji normalitas, diperoleh harga L hitung lebih kecil dari L tabel sehingga dapat ditarik kesimpulan bahwa kedua kelas berasal dari populasi yang berdistribusi normal dengan hasil sebagai berikut:

Tabel 1. Hasil Uji Normalitas Awal Siswa

\begin{tabular}{lcc}
\hline Sampel & $\mathrm{L}_{\text {hitung }}$ & $\mathrm{L}_{\text {tabel }}$ \\
\hline Kelas & 0,1242 & 0,1476 \\
Eksperimen & & \\
\hline Kelas Kontrol & 0,1147 & 0,1476 \\
\hline
\end{tabular}

Berdasarkan uji homogenitas, diperoleh harga $F_{\text {hitung }}=1,7071$ dan harga $\mathrm{F}_{\text {tabel }}=\mathrm{F}_{(0,025,35,35)}=1,961$. Terlihat bahwa $\mathrm{F}_{\text {hitung }}=1,7071$ lebih kecil dari $\mathrm{F}_{\text {tabel }}$ maka dapat disimpulkan bahwa kelas eksperimen dan kelas kontrol memiliki variansi sama atau homogen. Sedangkan untuk uji keseimbangan, diperoleh harga $t_{\text {hitung }}=$ 0,6668 dan harga $t_{\text {tabel }}=t_{(0,025,70)}=1,994$. Dapat dilihat bahwa -1,994 lebih besar dari 0,6668 dan 0,6668 lebih kecil dari1,994 maka dapat disimpulkan bahwa kelas eksperimen dan kelas kontrol memiliki kemampuan awal yang sama.

Untuk nilai tes prestasi belajar kelas $\mathrm{X}$ MIPA 3 diperoleh banyak sampel $(n)=36$, nilai terendah $=68$, nilai tertinggi $=100$, mean $(\overline{\mathrm{x}})=81,6667$, modus $=84$, median $=$ 82 , simpangan baku $(S)=8,678$, dan variansi $\left(S^{2}\right)=75,3142$. Sedangkan untuk kelas $X$ MIPA 4 diperoleh banyak sampel (n) $=36$, nilai terendah $=64$, nilai tertinggi $=100$, mean $(\overline{\mathrm{x}})=77,3333$, modus $=68,76,80$, median $=76$, simpangan baku $(S)=9,020$, dan variansi $\left(\mathrm{S}^{2}\right)=81,3714$.

Dari uji normalitas diperoleh L hitung lebih kecil dari $\mathrm{L}$ tabel sehingga dapat ditarik kesimpulan bahwa kelas eksperimen dan kelas kontrol berasal dari populasi yang berdistribusi normal dengan hasil sebagai berikut:

Tabel 2. Hasil Uji Normalitas Akhir Siswa

\begin{tabular}{lcc}
\hline \multicolumn{1}{c}{ Sampel } & $\mathrm{L}_{\text {hitung }}$ & $\mathrm{L}_{\text {tabel }}$ \\
\hline Kelas Eksperimen & 0,1173 & 0,1476 \\
\hline Kelas Kontrol & 0,1143 & 0,1476 \\
\hline
\end{tabular}

Untuk uji homogenitas diperoleh $\mathrm{F}_{\text {hitung }}=1,0804$ lebih kecil dari $\mathrm{F}_{\text {tabel }}=$ $\mathrm{F}_{(0,025,35,35)}=1,961$ sehingga dapat disimpulkan bahwa kelas eksperimen dan kelas kontrol memiliki variansi sama atau homogen. Sedangkan dari uji t diperoleh harga $t_{\text {hitung }}=2,0771$ lebih besar dari harga $\mathrm{t}_{\text {tabel }}=\mathrm{t}_{(0,025,70)}=1,994$ maka ada perbedaan berbedaan nilai rata - rata antara kelas eksperimen dan kelas control sehingga dapat disimpulkan bahwa ada pengaruh model pembelajaran kooperatif tipe Student Team Achievement Division (STAD) terhadap prestasi belajar matematika siswa kelas $\mathrm{X}$ MIPA 3 SMA Negeri 1 Weru tahun pelajaran 2019/ 2020.

Terlihat bahwa kelas yang menggunakan model pembelajaran kooperatif tipe Student Team Achievement Division (STAD) nilai rata - rata prestasi belajarnya lebih tinggi dari kelas yang menggunakan pembelajaran konvensional. Hal ini disebabkan pembelajaran menggunakan model pembelajaran STAD mengharuskan siswa bekerja sama dengan satu tim yang heterogen untuk mencapai keberhasilan. Artinya, dalam satu tim terdiri dari siswa dengan kemampuan tinggi, sedang dan rendah. Siswa dengan kemampuan tinggi dapat membantu anggotanya yang kesulitan memahami materi sehingga semua anggota kelompok dapat memahami materi dengan baik yang nantinya dapat meningkatkan keberhasilan kelompok maupun individu. Ini sesuai dengan tujuan model pembelajaran 
STAD menurut Priansa (2017: 320) yang menyatakan bahwa tujuan model pembelajaran kooperatif tipe STAD adalah menumbuhkan rasa tanggung jawab baik individu maupun kelompok sehingga memperoleh hasil yang memuaskan dan Isjoni (dalam Priansa, 2017: 320) yang menyatakan bahwa tujuan penggunaan STAD adalah untuk mengubah perilaku belajar peserta didik dari individualistik menjadi kerja sama tim yang mendorong peserta didik untuk saling membantu satu dengan yang lainnya

Dengan demikian, penggunaan model pembelajaran kooperatif tipe Student Team Achievement Division (STAD) berpengaruh positif terhadap prestasi belajar siswa. Pengaruhnya adalah dapat meningkatkan prestasi belajar matematika siswa kelas $\mathrm{X}$ MIPA 3 SMA Negeri 1 Weru tahun pelajaran 2019/2020.

\section{KESIMPULAN}

Berdasarkan hasil analisis data dan pembahasan, dapat disimpulkan bahwa ada pengaruh model pembelajaran kooperatif tipe Student Team Achievement Division (STAD) terhadap prestasi belajar matematika siswa kelas X MIPA 3 SMA Negeri 1 Weru tahun pelajaran 2019/2020.

\section{Daftar Pustaka}

Arikunto, Suharsimi. (2013). ProsedurPenelitian. Jakarta: Rineka Cipta.

Giyanti. (2018). Pengaruh Model Pembelajaran Kooperatif Student Team Achievement Division (STAD) Dan Rasa Percaya Diri Siswa Terhadap Hasil Belajar Matematika Siswa SMA. GAUSS: Jurnal Pendidikan Matematika. Volume 1. Nomor 1. Halaman 43.

Hamdani. (2011). Strategi Belajar Mengajar. Bandung: CV. Pustaka Cipta

Hidajat, Djatmiko, Dewi Susilowati, Andhika Ayu Wulandari. (2018). Pengaruh Penggunaan Miniatur Mobil Terhadap Prestasi Belajar Matematika.
Eudikara: Jurnal Pendidikan dan Pembelajaran. Volume 3. Nomor 1. Halaman 16.

Priansa, Donni Juni. (2017). Pengembangan Strategi dan Model Pembelajaran. Bandung: CV.Pustaka Setia

Susanto, Herry Agus. (2012). Nilai Matematika Dan Pendidikan Matematika dalam Pembentukan Kepribadian. Jurnal Pendidikan Dan Pembelajaran. Volume 19. Nomor 1. Halaman 118.

Thaib, Eva Nauli. (2013). Hubungan Antara Prestasi Belajar Dengan Kecerdasan Emosional. Jurnal Ilmiah DIDAKTIKA. Volume 13. Nomor 2. Halaman 387. 